\title{
Sentidos atribuídos por jovens escolares LGBT à afetividade e à vivência da sexualidade
}

\section{Meanings attributed to affectivity and experience of sexuality by LGBT school youths}

\section{Sandra Freitas ${ }^{\mathrm{a}}$}

(D) https://orcid.org/0000-0002-5565-7849

E-mail: sandrashamsa®gmail.com

\section{Ximena Pamela Díaz Bermúdez ${ }^{\mathrm{a}}$}

(i) https://orcid.org/0000-0002-3771-7684

E-mail: ximenapam®gmail.com

\section{Edgar Mérchan-Hamann ${ }^{a}$}

(D) https://orcid.org/0000-0001-6775-9466

E-mail: merchan.hamannळgmail.com

anniversidade de Brasília. Faculdade de Ciências de Saúde. Programa de Pós-Graduação em Saúde Coletiva. Brasília, DF, Brasil.

\section{Correspondência}

Sandra Freitas

Universidade de Brasília. Faculdade de Ciências de Saúde. Programa de Pós-Graduação em Saúde Coletiva. Campus Universitário Darcy Ribeiro. Asa Norte. Brasília, DF, Brasil. CEP 70910-900.

\section{Resumo}

Este artigo é um estudo sobre narrativas de jovens escolares autoidentificadas como parte de segmentos sociais de lésbicas, gays, bissexuais e pessoas trans (LGBT), que atuaram como protagonistas em projetos de promoção da saúde e defesa dos direitos humanos em contextos escolares. O estudo utilizou estratégias metodológicas de natureza qualitativa, tais como o registro da história de vida e entrevistas em profundidade, visando compreender os significados atribuídos às ações desenvolvidas nos projetos e aspectos das experiências vividas. Participaram do estudo uma mulher trans, um homem cis gay e uma mulher cis lésbica, que durante três meses e em diversos cenários dialogaram nas entrevistas. Este artigo contempla quatro categorias centrais identificadas nas narrativas: identidades e diversidade, mapa das violências, vivências afetivo-sexuais de jovens escolares LGBT e promoção da saúde de jovens LGBT no cenário escolar. As violências descritas abrangem aspectos físicos, psicológicos, sexuais, negligência e abandono. A discriminação na família e na escola surgiu como marca de sofrimento. Conclui-se que os projetos de educação em sexualidade e direitos humanos em âmbito escolar podem ser considerados oportunidade de conhecimento e troca entre pares e facilitadores de uma vivência mais humana e protetora da afetividade e da sexualidade de jovens LGBT. Para o processamento e classificação das narrativas foi utilizado o software Atlas Ti, versão 8 . Palavras-chave: Sexualidade; Direitos Humanos. 


\section{Introdução}

This paper studies the narratives of young school students self-identified as part of the social segments of lesbians, gays, bisexuals and trans people (LGBT), who acted as protagonists in projects to promote health and defend human rights in school contexts. The study is based on qualitative methodological approach such as life history and in-depth interviews, aiming to understand the meanings attributed to the actions developed in the projects and their life experiences. For three months and in different settings a trans woman, a gay cis man and a lesbian cis woman participated in the interviews, sharing their life experience. The paper analyses four essential categories identified in the narratives: identities and diversity, map of violence, sexual affective experiences of LGBT students and health promotion of LGBT youths in the school setting. The described violence shows physical, psychological and sexual aspects, as well as neglect and abandonment. Discrimination in the family and at school scenarios emerged as a mark of suffering. We conclude that education projects on sexuality and human rights in schools can be considered an opportunity for knowledge and exchange between peers, allowing for a more humane and protective experience of the affectivity and sexuality of young LGBT people. Atlas Ti version 8 supported the data processing and codification.

Keywords: Sexuality; Human Rights.
Este artigo trata de vivências narradas por adolescentes e jovens lésbicas, gays, bissexuais, travestis, transexuais e transgêneros (LGBT) participantes de projetos de promoção da saúde no espaço escolar. Importa, porém, definir preliminarmente o que é ser adolescente ou jovem. Para a Organização Mundial de Saúde (OMS), a adolescência é um período entre 10 e 19 anos com intensas mudanças biológicas e psicossociais, enquanto a juventude abrange dos 15 aos 24 anos. No Estatuto da Criança e do Adolescente (ECA), a adolescência se verifica entre 12 e 18 anos incompletos. No Estatuto da Juventude, que trata dos direitos, princípios e diretrizes de políticas públicas dos jovens, esse período é definido entre 15 e 29 anos. No entanto, entender adolescência e juventude requer uma compreensão mais ampla do que considerar apenas aspectos cronológicos da idade.

O termo "juventude", sociologicamente, apresenta algumas perspectivas. Pais (1990) propõe a classificação em correntes, sendo a geracional, que privilegia fatores etários e aspectos biológicos, aproximando-se de uma dimensão mais universalista dos jovens, e outra, a classista, que assume a juventude como um fenômeno influído pelos marcadores sociais de inserção dos jovens em diferentes classes sociais, experiências de vida e formas de integração social. Bourdieu (1983) argumenta que classificar juventude considerando apenas fatores etários e biológicos não permite entender o conceito na complexidade de suas dimensões. Outras perspectivas se apresentam na forma como os jovens se inserem no mundo e nas práticas e projetos de vida vinculados aos sentidos dados à vida e às relações sociais estabelecidas nos diversos contextos.

O protagonismo juvenil LGBT em espaço escolar propõe reflexões que podem ampliar as percepções e outorgar novos sentidos às vivências da sexualidade e da afetividade, potencializando o papel da juventude no mundo contemporâneo. 0 termo LGBT é usado para representar a diversidade sexual e de gênero, mas outras inserções têm sido desenhadas pela assunção da visibilidade, como a sigla LGBTQI+, em que "Q" se refere ao vocábulo inglês queer, originalmente usado de modo pejorativo, tal como fag e fagot em inglês, 
bent em alemão, marica em espanhol ou viado em português. Queer foi ulteriormente ressignificado pelas contribuições teóricas de vários estudiosos, inclusive de Butler (2002), que faz uma leitura crítica das normatizações performáticas e hierárquicas coercitivas de gênero. A denominação "I" é utilizada para o reconhecimento da pessoa intersexual e o (+) na perspectiva de outras categorias de gênero. Ainda, segundo Jesus (2012), o "sexo" normalmente é definido biologicamente e o gênero traduz questões sociais, com base em tais pressupostos, o ser humano recebe uma designação de "gênero" ao nascer. Assim, quando uma pessoa se identifica com o "gênero" que a caracterizou no nascimento, é classificada como cisgênera (cis) e, quando esse "gênero" difere de sua identidade, ela é classificada como transgênero (trans). Como não existe consenso em relação ao uso desses termos no meio acadêmico, a utilização dos termos cis e trans para se referir às participantes de pesquisa se deve à sua menção pelas próprias jovens em suas narrativas.

O foco deste estudo é refletir sobre saúde e sexualidade, temas presentes nas concepções e práticas de adolescentes e jovens que frequentam espaços escolares. Também objetivamos direcionar o pensamento para o papel das escolas como espaços privilegiados para uma educação em saúde e promoção de práticas e intervenções que contribuam para o bemestar dessa população, uma vez que ser jovem LGBT no espaço escolar constitui um desafio, diante dos avanços e retrocessos da política educacional no Brasil.

Apontamentos históricos retratam que discutir sexualidade, principalmente em escolas, durante a ditadura militar, não era bem-visto pela moral conservadora vigente (Bedin, 2016). Nos anos 1980, com o afrouxamento da censura, a preocupação de se levar o debate para as escolas ressurge embalada pela resposta à epidemia de HIV/aids e pelo aumento do número de gravidezes na adolescência em escolas. Apenas em 1997, os Parâmetros Curriculares Nacionais (PCN) propiciaram o reconhecimento oficial quanto à necessidade de se estabelecer diálogo, de forma transversal, sobre educação em sexualidade nas escolas, apesar do discurso higienista e biologizante vigente (Bueno; Ribeiro, 2018). No entanto, foi apenas entre 2003 e 2011 que políticas de inclusão social possibilitaram aproximação com movimentos sociais LGBT, viabilizando um incremento na produção acadêmica sobre a matéria, aumentando a visibilidade das temáticas de gênero e diversidade sexual nas políticas educacionais e colocando em pauta questões ainda consideradas tabu no ambiente escolar.

Importante compreender que o projeto escolar que abrigou as experiências aqui narradas teve início em um momento de reconhecimento do papel do Estado e das políticas públicas de saúde e educação em relação à escola. À medida que o projeto se desenvolvia, foi implementado, em 2003, o projeto Saúde e Prevenção nas Escolas (SPE), que validava a prevenção de HIV/ aids e a educação em sexualidade e direitos humanos em âmbito escolar. Em 2004, o Conselho Nacional de Combate à Discriminação deu continuidade a essa estratégia, publicando o documento "Brasil Sem Homofobia: Programa de combate à violência e à discriminação contra LGTB e de promoção da cidadania homossexual", ficando expressa a política intersetorial de enfrentamento da homofobia. A partir de 2007, surge o Programa Saúde na Escola (PSE), com previsão de fortalecimento de ações para desenvolvimento integral e participação da comunidade em programas e projetos de saúde e educação (Brasil, 2011).

Gradualmente foram criadas abordagens sobre direitos humanos nas escolas a partir de 2003 , porém, somente em 2012, foram estabelecidas as Diretrizes Nacionais para Educação em Direitos Humanos (EDH) em cenário escolar (Beleche; Silva, 2017). Tais diretrizes tiveram o intuito de articular espaços de debate, formação continuada e instituição de redes de apoio na comunidade escolar, bem como adotar, nesse ambiente, a redução de vulnerabilidades individuais e sociais, construindo espaços de respeito à diversidade, combate à violência e instituição de mecanismos de proteção.

Por outro lado, em 2004, no campo político, iniciava-se o movimento Escola sem Partido, afirmando representar pais e estudantes contrários ao que seus defensores denominavam de "doutrinação ideológica” nas escolas, tentando, dentre vários retrocessos, excluir temas e termos como orientação sexual e gênero do Plano Nacional da Educação (PNE) e da Base Nacional Comum Curricular (BNCC). A bancada conservadora foi se fortalecendo no poder, ensejando o arrefecimento das ações e desmonte das políticas arduamente conquistadas. Com o país dividido politicamente, principalmente a partir de 
2014, o movimento Escola sem Partido ganhou mais espaço. Atualmente, verifica-se um retrocesso quanto à inclusão desses temas nas agendas escolares, a exemplo de sexualidade, gênero e direitos humanos, suprimidos de documentos relevantes para o suporte legal a ações vinculadas à formação da cidadania.

Segundo Neves (2017), ao longo de 2014, previase a minimização das desigualdades com ênfase na promoção da equidade racial, gênero e orientação sexual no PNE e BNCC; entretanto, o texto aprovado excluiu tais propósitos e o governo continua engessando espaços de liberdade de expressão, potencializando o preconceito e a discriminação de jovens LGBT. Para Deslandes (2015), isso ameaça a construção de valores democráticos na sociedade. Adicionalmente, concepções religiosas imbricadas em cenário político têm eclipsado a laicidade do Estado e estimulado o estigma, a discriminação e a vulnerabilidade à violência direcionada a tais segmentos da juventude (Silva; Paiva; Parker, 2013). Apesar disso, algumas escolas persistem em tentar ampliar espaços para a discussão contra-hegemônica de direitos, sexualidade e afetividade de jovens.

Neste artigo, além das experiências das jovens protagonistas como interlocutoras com seus pares em escola, pretende-se também compreender como enfrentam a afetividade e sexualidade e os significados atribuídos às suas trajetórias de vida e em projeto escolar.

\section{Metodologia e contexto}

Estudo qualitativo a partir da sistematização de narrativas e histórias de vida de três jovens LGBT, ex-alunas de uma escola que desenvolvia projetos de promoção à saúde onde foram protagonistas e coordenadoras dessa iniciativa em diversos ambientes. Durante três meses, as jovens foram acompanhadas pela pesquisadora em 29 encontros. Foram desenvolvidas entrevistas semiestruturadas com base em um roteiro préestabelecido, que abordou os seguintes assuntos: trajetória escolar, qualidade das relações familiares e em sociedade, facilidades e dificuldades da vivência da sexualidade e afetividade, envolvimento como protagonistas nas ações de educação em sexualidade, direitos humanos e saúde em escolas.
A pesquisa teve lugar no âmbito de um projeto em uma escola pública, desde 2001.

O projeto escolar trouxe reflexões críticas que fomentaram a formação de jovens protagonistas na metodologia de educação entre pares. A experiência foi apresentada em fórum internacional e também foi reconhecida por organizações nacionais e estrangeiras. Atualmente, o projeto se tornou organização não governamental (ONG), com o objetivo de continuar promovendo a construção cidadã de jovens. Em sua coordenação, como reflexo de resistência, jovens LGBT, majoritariamente, ditam o ritmo das ações.

Os dados das entrevistas foram confrontados com anotações de diário de campo a partir de percepções, expressão corporal e representações simbólicas apreendidas no decorrer da pesquisa. As entrevistas transcritas foram analisadas pelo software Atlas TI 8. O material narrativo foi classificado a partir das unidades de significado, seguindo o método de análise de conteúdo de Bardin (1977). Os dados foram selecionados em quotations, representados como trechos significativos das transcrições, codes como frases e palavras que resumiram trechos relevantes e code groups, representando as categorias centrais de análise. A pesquisa observou as considerações éticas envolvendo seres humanos, em conformidade com as normas vigentes, e o projeto foi aprovado pelo Comitê de Ética em Pesquisa da Faculdade de Saúde da Universidade de Brasília (CEP/FS/UnB), sob número 2.270.313.

\section{Resultados e discussão}

Três jovens LGBT foram as participantes do estudo. Uma mulher trans de 20 anos, ex-aluna da escola, onde iniciou o processo de aceitação de sua travestilidade, um homem cis gay de 20 anos, que se envolveu com o projeto quando estudante, e uma jovem mulher cis lésbica de 17 anos, que ao conhecer o projeto colaborou com atividades dentro e fora da escola. Atualmente, todas elas, direta ou indiretamente, colaboram com a ONG.

A partir da leitura flutuante das narrativas e da seleção dos trechos significativos das transcrições, emergiram para a concepção deste artigo quatro categorias centrais: Categoria I - Identidades e Diversidade; Categoria II - Mapa das Violências; 
Categoria III - Vivências afetivossexuais de jovens escolares LGBT; e Categoria IV - Promoção da saúde de jovens LGBT em cenário escolar. Os resultados produziram quatro figuras representativas denominadas networks, apresentadas a seguir.

\section{Categoria I: Identidades e Diversidade}

$\mathrm{Na}$ categoria Identidades e Diversidade surgiram descobertas acerca da identidade, medo da não aceitação social e sentimentos de negação. Negar a identidade LGBT pode ser consequência da homofobia internalizada, termo cunhado por Alan Malyon (1982), que expressa o autopreconceito e o autodesprezo em decorrência de desejos e comportamentos alheios às normas cisheteronormativas e que, internalizados por pessoas LGBT, dificultam o processo de aceitação e assunção de sua sexualidade e identidade e contribuem para a estigmatização dos pares. Por outro lado, as jovens expressaram reforço da identidade e de "empoderamento", introspecção e luta pelo pertencimento, permitindo um olhar diversificado e original sobre si, como expresso na Figura 1.

Figura I - Categoria I: Identidades e Diversidade com algumas subcategorias: quem sou, como me sinto, meu desejo e singularidades

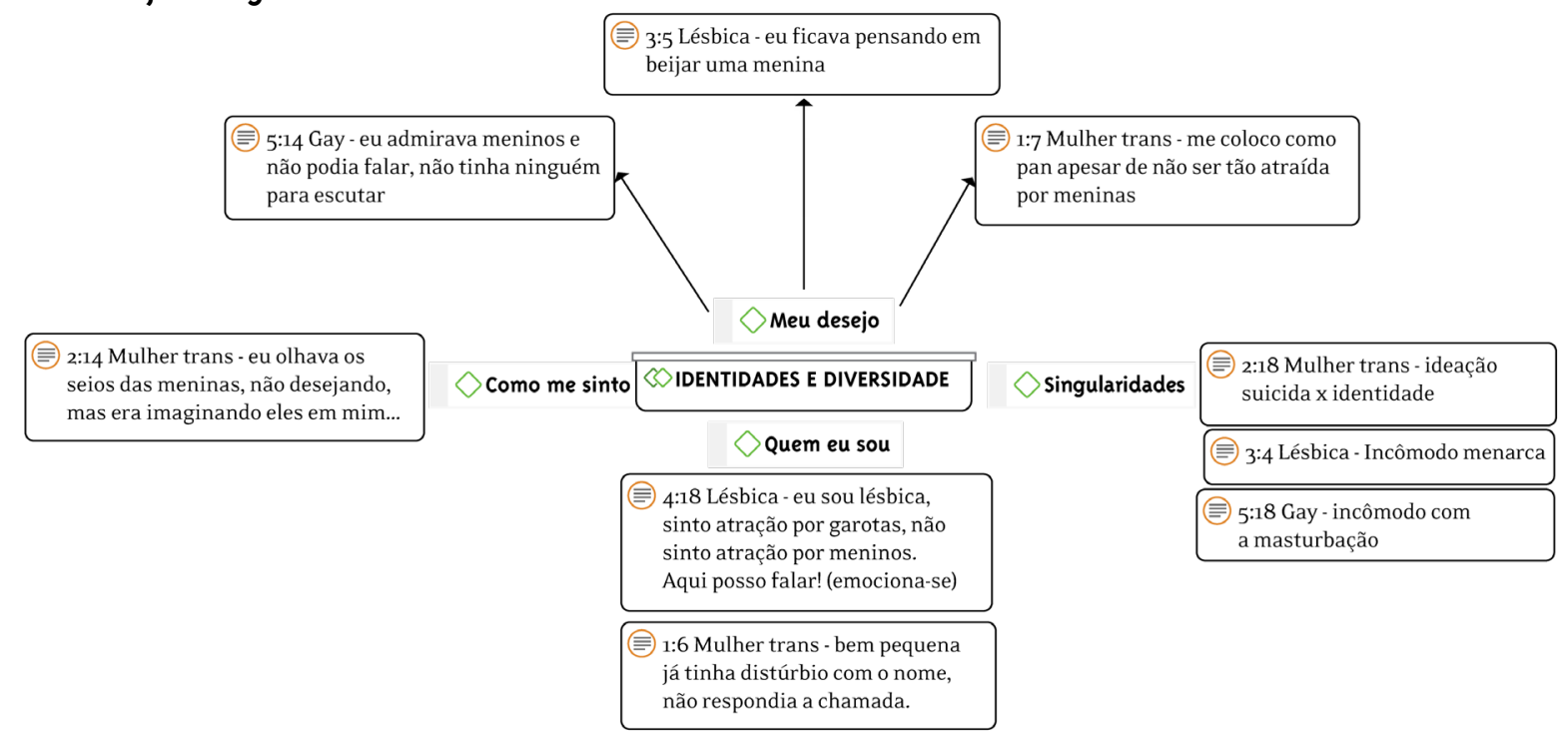

Algumas convergências e singularidades foram percebidas nas identidades das jovens participantes da pesquisa. A identidade de gênero pode ser vivenciada de várias formas e, assim, a heteronormatividade ou o binarismo atribuído pelo sexo biológico e pelo gênero, como masculino e feminino, não mais responde às diversas identidades possíveis ou às formas de afetividade vividas na atualidade (Spargo, 2017).

Na Figura 1 da network, as convergências classificaram a categoria identidade a partir dos códigos "como me sinto" e "quem sou". A mulher cis lésbica relatou que "eu não gostava daquelas coisas, não eram roupas masculinas que eu usava, começaram a dizer que eu estava querendo ser menino e não tinha nada a ver". A mulher trans relatou que, antes do processo de assunção da nova identidade, ao observar os seios das amigas, não sentia atração, mas sim vontade de tê-los e se sentia mal por isso. Em todas as falas, percebeu-se sofrimento ou dificuldade em se assumir LGBT. O jovem gay, por exemplo, disse "Eu não queria ser, tinha medo, por conta de trejeitos, quando falavam que eu parecia viado, eu chorava muito...?" Constata-se, portanto, que assumir identidade nunca foi simples, pois ela é dinâmica, instável e não estabelecida, mas sempre passível de transformação (Louro, 2017).

A orientação sexual traduzida como a subcategoria Meu Desejo foi o despertar mais doloroso percebido nas narrativas, pois evidenciou culpa, solidão, exclusão, medo e sofrimento, o que, segundo Spargo (2017), marca 
a transgressão por não seguir a norma imposta pela sociedade, que privilegia a cis-heteronormatividade. A percepção desses sentimentos surgiu de alguns relatos, como o termo "pan" utilizado pela mulher trans para representar a atração que sentia por pessoas, independentemente de sua identidade sexual, gênero, orientação sexual ou sexo biológico. A jovem lésbica se sentia atraída, mas culpada pelo desejo de beijar meninas. A solidão relatada pelo jovem gay quando percebeu que desejava garotos, mas não tinha ninguém para compartilhar tais sentimentos.

Outro aspecto identificado foi o desconforto da mulher trans desde criança com o nome civil: "desde criança já tinha um distúrbio com o nome, falava que era Matheus, João; ficava inventando, não respondia à chamada". Essa situação pode retratar o desconforto desde a mais tenra idade, sinalizando a transexualidade não como opção, mas como identidade de gênero. Para se assumir cidadã LGBT, foi necessária uma profunda reconstituição na sua autoestima e autoconfiança. O relato da jovem mulher cis “olha, eu sou lésbica, amo garotas, sinto atração por garotas e não sinto atração nenhuma por garotos. Aqui eu posso dizer isso!" pressupõe um percurso por diversas etapas de reconhecimento, que implicaram processos de encorajamento e ressignificação a partir da aproximação de espaços de liberdade e expressão no âmbito da escola.

A subcategoria Singularidades exprime sentimentos, como a ideação suicida constante da mulher trans, resultado do sofrimento por sentir ter nascido em corpo errado. Muitos estudiosos admitem que a experiência transgênero, na chamada transfobia internalizada, reflete uma guerra da pessoa com seu próprio corpo, acarretando angústia e ansiedade na relação com sua anatomia. Outro sentimento nessa subcategoria verificou-se no pavor do jovem gay quando se percebe vivenciando a culpa na masturbação, o que indica que mitos e tabus em sexualidade não assolam apenas a sociedade cis-heteronormativa, mas de forma geracional podem estar relacionados com todos os indivíduos, independentemente de sua orientação sexual.

\section{Categoria II: Mapa das Violências}

Observou-se nesta categoria a marca de agressividade e hostilidades como elementos presentes nas trajetórias LGBT. Na Figura 2, percebese que as narrativas referem episódios de diversos tipos de violência, todos destacados na literatura sobre o tema.

Figura 2 - Categoria II: Mapa das Violências segundo as subcategorias: violência física, violência sexual, violência psicológica e negligência e abandono

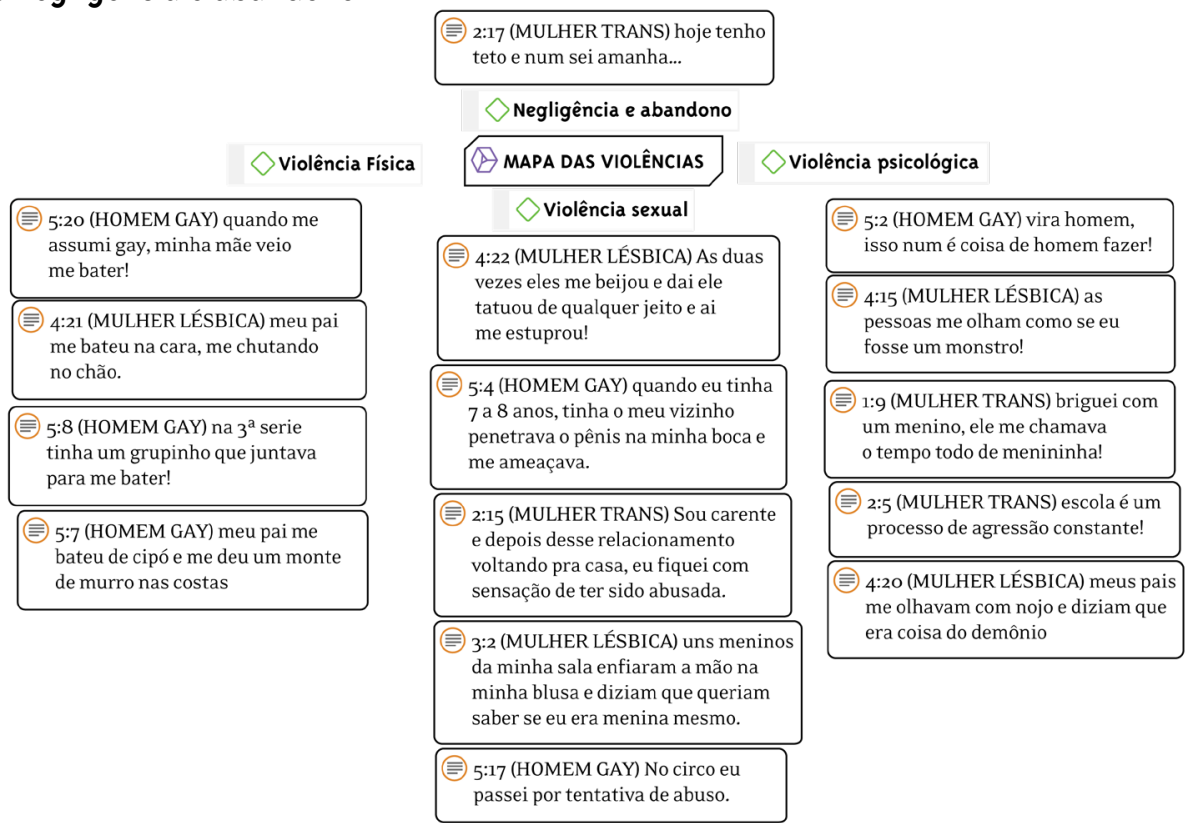


As diversas formas de manifestação de violência narradas pelas jovens LGBT indicam que este é um fenômeno recorrente no seio familiar, que revela a centralidade da valorização de relações heteronormativas com influências morais e religiosas e a resposta particularmente dolorosa no âmbito dessas estruturas sociais (Silva; Paiva; Parker, 2013). As narrativas expressam que a vivência da sexualidade e a construção da identidade de gênero estão sujeitas a mecanismos de opressão em diversas escalas sociais. Nas narrativas analisadas, a violência física foi aplicada como medida corretiva dos pais quando do conhecimento das identidades mais fluidas das filhas.

Quando a família rejeita com violência um comportamento por considerá-lo sujo e fora das normas de bons costumes, amplia-se um retrato opressor e a pessoa passa a se sentir agredida em outros ambientes. Constata-se isso, por exemplo, na fala de uma delas: "escola é um processo de agressão constante!" (Mulher trans, 20). Assim, sair desse ciclo é um desafio imenso.

A violência sexual relatada pelas participantes de pesquisa se manifestou como resultado de um processo de vulnerabilidade. Nota-se o aumento da prática do estupro na sociedade, podendo-se inferir que ser lésbica afronta a cultura machista de controle dos corpos e da sexualidade feminina. Nessa linha, o "estupro corretivo" pode estar fundamentado em ódio e preconceito, como tentativa de se converter a orientação sexual da vítima em heterossexual, fortalecendo as masculinidades conservadoras e patriarcais (Silva, 2017).

A jovem lésbica sofreu violência quando o tatuador cobrou dela uma relação sexual forçada pelo trabalho como mecanismo de comprovação de sua orientação sexual. Tendo se sentido exposta e ameaçada a sofrer novas violências, a jovem optou pelo silenciamento. Outro evento relatado por ela remonta aos 10 anos de idade, quando os colegas de classe tocaram o seu corpo sem consentimento: "uns meninos da minha sala colocaram a mão embaixo da minha blusa e diziam que queriam ver se eu era menina mesmo. Os outros colegas viram e não falaram nada, uma professora me viu chorando e fez pouco caso" (Mulher cis lésbica, 17). O jovem gay também foi vítima de vários eventos de violência sexual, relatando que "o meu vizinho colocava o pênis na minha boca e me ameaçava”. Embora a mulher trans mencione vagas lembranças de que sofreu violência sexual, não detalhou como aconteceram, eles estavam expressos nas entrelinhas de suas narrativas.

No contexto de preconceito e discriminação, vários trechos ilustram momentos que produziram sofrimento nas trajetórias das jovens protagonistas. Seus depoimentos ratificam as afirmações de Braga et al. (2018) e Silva (2017), para os quais preconceito, discriminação e sofrimento podem levar a processos de adoecimento no campo da sexualidade e da saúde mental, como depressão, ansiedade, isolamento, uso abusivo de álcool e/ou outras drogas e até ideação suicida. Estudos brasileiros com metodologias diversas têm mostrado que a violência e suas diversas manifestações estão presentes no cotidiano de jovens LGBT.

Na população de homens que fazem sexo com homens, abordados pelo método de pesquisa Respondent Driven Sampling (RDS), foi constatada a associação entre violência sexual e discriminação com base em orientação sexual, sintomas de infecção sexualmente transmissível e ideação suicida (Sabidó et al., 2015).

Os dados coletados são corroborados por estudos epidemiológicos que, a partir da década de 1980, já mostravam maior frequência de ideação suicida entre jovens LGBT, quando comparados com heterossexuais. Os resultados dessas pesquisas foram posteriormente reafirmados em estudos de base populacional e com vários desenhos metodológicos (Russel; Joyner, 2001). Outros autores mostraram que alguns fatores estão associados a tentativas de suicídio, alguns deles relatados pelas participantes deste estudo, como sensação de desesperança, falta de apoio familiar e depressão, entre outros (Mustanski; Liu, 2013).

\section{Categoria III: Vivências afetivo-sexuais de jovens escolares LCBT}

Embora as vivências da sexualidade e afetividade estejam longe de ser direito de fato para a população LGBT, o cenário escolar com 
espaços para o protagonismo juvenil pode promover fortalecimento e desconstrução de preconceitos alinhavados por históricos de negação de direitos e desrespeito à diversidade sexual e de gênero.
As jovens relataram facilidades e dificuldades na vivência da própria sexualidade e afetividade, trazendo reflexões e desafios no enfrentamento de violências, conforme demonstrado na Figura 3.

Figura 3 - Categoria III: Vivências afetivo-sexuais de jovens escolares LGBT com as subcategorias: facilidades $e$ dificuldades de vivenciar sexualidade e afetividade no contexto das trajetórias de vida

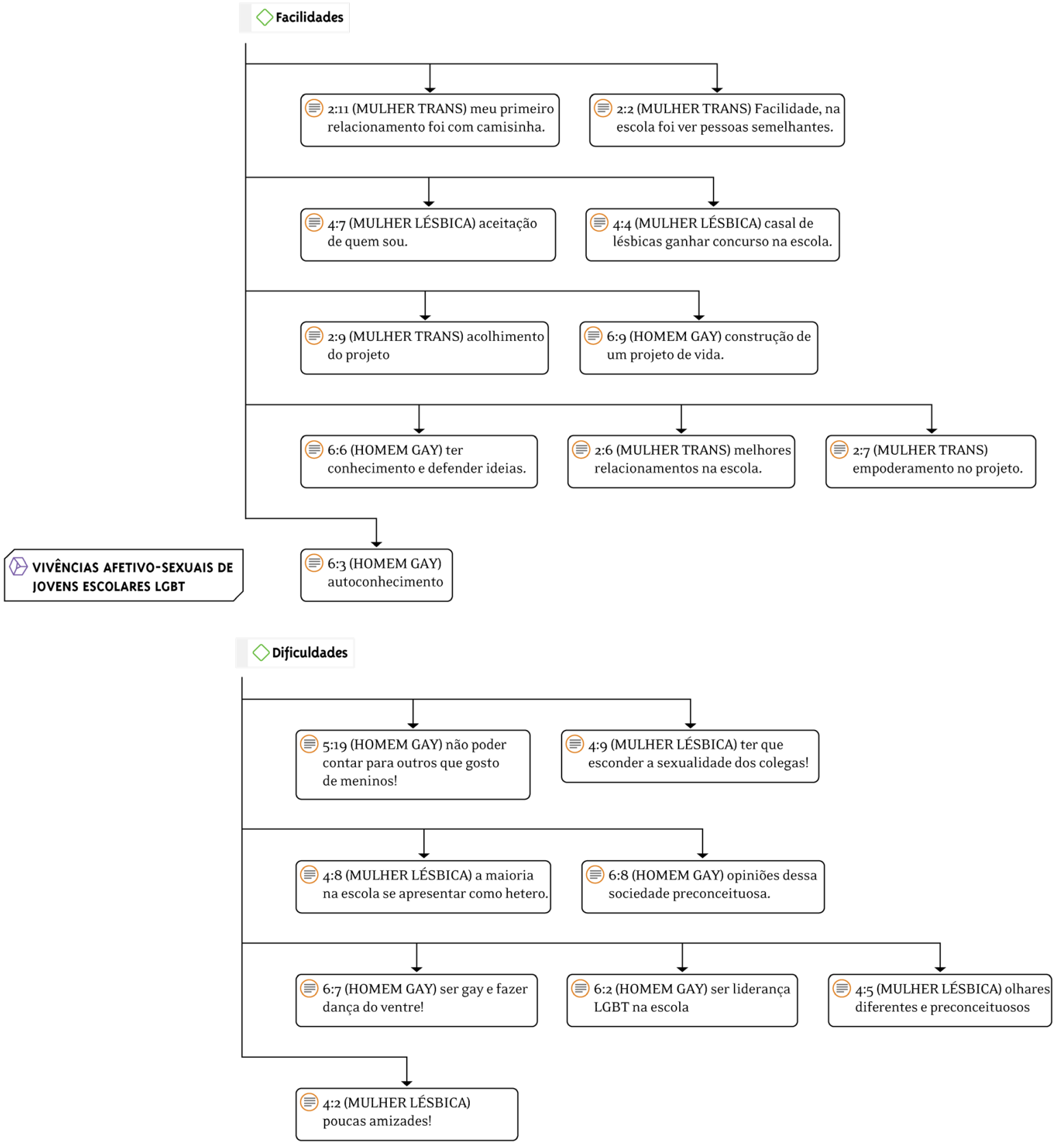


A partir de contribuições teóricas de Foucault (1988), e mais expressivamente, com o surgimento da Teoria Queer, postula-se a necessidade de se romper com o binarismo sexual e de gênero na análise acadêmica. A própria conceituação da sexualidade nas discussões contemporâneas surge de reflexões influenciadas pelo pós-estruturalismo que retira, aos poucos, a leitura do controle do poder sexual masculino do centro do debate e dá voz ao feminino pelo reconhecimento da alteridade. No contexto de releituras feministas da realidade (Rubin, 1984), que precederam a perspectiva teórica queer (Butler, 1990), é reconhecido que as práticas discursivas em torno do sexo e gênero são socialmente construídas e não mais vistas como "naturais", na perspectiva essencialista. Nessa visão, questões de gênero, sexualidade, desejo, sentimentos, prazer e autorreconhecimento como seres sexuados passam a promover novos rumos, tendo implicações políticas relevantes.

As maiores dificuldades das trajetórias das jovens transpareceram em falas relacionadas à própria identidade e ao impacto da violência, preconceito, estigma, discriminação e sofrimento vivenciados, inclusive no espaço familiar. O jovem gay retratou que nunca existiu escuta familiar sobre os seus desejos e teve sempre que suportar olhares preconceituosos daqueles mais próximos. Esse fato evidencia a existência de exaltação à heteronormatividade compulsória, com a imposição de um silenciamento que intimida e impede a assunção da sexualidade, isola e reprime os gostos.

Embora com todos esses dificultadores, a aproximação e inserção das jovens entrevistadas no projeto tornaram-se um canal de fortalecimento das suas identidades, conforme declarado em algumas falas: "ter sido acolhida e aprender a compartilhar conhecimentos pelo projeto", "percebi aqui outros semelhantes a mim e facilitou meu empoderamento" (Mulher trans, 20), "na minha primeira vez usei camisinha, pois aprendi a importância no projeto" e "comecei aqui a construir o meu projeto de vida" (Homem cis gay, 20) e "fiquei surpresa de ganhar um concurso na escola no dia dos namorados mesmo sendo lésbica" (Mulher cis lésbica, 17). Nesse espaço, as jovens se depararam com a possibilidade de ter direito a voz sobre suas experiências na sexualidade e afetividade, revelando e desconstruindo mitos e preconceitos em torno do tema como parte do papel social da escola.

Nos Estados Unidos, apesar de muitas dificuldades, tais desafios têm sido assumidos pelos administradores das escolas com base na legislação federal de direitos civis, ${ }^{1}$ que proíbe a discriminação sexual nos programas e atividades educacionais (Kurt; Chenault, 2017). Para Duque e Teixido (2016), é preciso ir além da preocupação com a orientação sexual e de gênero de estudantes, devendo tal esforço envolver toda a comunidade escolar. Na esfera internacional, vários países referem violência no ambiente escolar sob a forma de bullying, destacando-se a homofobia, lesbofobia e transfobia. Isso ocorre inclusive em países católicos, nos quais a política de prevenção da violência nas escolas inclui especificamente a consciência da determinação de gênero (Duque; Teixido, 2016).

\section{Categoria IV: Promoção da saúde de jovens LGBT em cenário escolar}

Jovens LGBT em ações de protagonismo coadunam com processos de fortalecimento da promoção da saúde em espaço escolar. Esta categoria responde a uma parte do objetivo da pesquisa, por compreender e identificar interfaces entre o projeto cenário de pesquisa e a promoção da saúde em contexto escolar. Buscou-se entender em que medida tal iniciativa promove ou não saúde em âmbito escolar e na vida dos jovens LGBT. A seguir apresenta-se a network que resume a subcategoria Projeto e significados e posterior diálogo com a literatura.

1 The Civil Rights Act of 1964 - marco dos direitos civis que proibiu a discriminação de gênero nas escolas americanas. 


\begin{tabular}{|c|c|c|c|}
\hline & \multicolumn{2}{|c|}{$\begin{array}{l}\text { COROMOÇÃO DA SAÚDE DE JOVENS LGBT } \\
\text { EM CENÁRIO ESCOLAR }\end{array}$} & \\
\hline & \multicolumn{2}{|c|}{ PROJETO E SIGNIFICADOS } & \\
\hline $\begin{array}{l}\text { 15:9 (MULHER TRANS) Na dança foi } \\
\text { nascendo a profissional pelo estudo e } \\
\text { observando a minha professora. }\end{array}$ & \begin{tabular}{|l|} 
6:2 (HOMEM CIS GAY) o meu maior \\
prazer hoje é esta no projeto e fazer pelos \\
outros o que o projeto fez \\
por mim.
\end{tabular} & $\begin{array}{l}\text { 29:6 (MULHER CIS LÉSBICA) O projeto } \\
\text { de entrar nas salas, com toda a } \\
\text { dinâmica que a gente faz é muito } \\
\text { importante. Muda alguns alunos, apesar } \\
\text { de não mudar todos já é muito bom. }\end{array}$ & $\begin{array}{l}\text { 35:5 (MULHER CIS LÉSBICA) Ter } \\
\text { entrado no educando talvez tenha } \\
\text { revolucionado a minha vida mais do que } \\
\text { imaginava. Tem ajudado a me aceitar e } \\
\text { a me relacionar melhor com as pessoas. }\end{array}$ \\
\hline $\begin{array}{l}\text { 35:6 (MULHER CIS LÉSBICA) O projeto } \\
\text { me ajudou a me relacionar melhor com } \\
\text { as pessoas e comigo mesma. }\end{array}$ & $\begin{array}{l}\text { 7:2 (HOMEM CIS GAY) gosto de ver } \\
\text { funcionar o projeto na escola e espero } \\
\text { que ele chegue em todos os turnos. }\end{array}$ & \multirow{2}{*}{$\begin{array}{l}\text { 6:11 (HOMEM CIS GAY) Jamais esperava } \\
\text { coordenar nada na minha vida, hoje sim, } \\
\text { ganhei credibilidade e autonomia, é } \\
\text { gratificante e é amar. }\end{array}$} & \multirow{2}{*}{$\begin{array}{l}\text { 29:5 (MULHER CIS LÉSBICA) no projeto } \\
\text { eu fui pegando mais essa aceitação } \\
\text { sabe? de ser lésbica. }\end{array}$} \\
\hline \multirow{2}{*}{$\begin{array}{l}\text { 14:27 (MULHER TRANS) } 0 \text { projeto já } \\
\text { tinha uma demanda imensa e quando } \\
\text { percebi já estava envolvida com tudo. }\end{array}$} & \multirow{2}{*}{$\begin{array}{l}\text { 6:12 (HOMEM CIS GAY) o que mais gosto } \\
\text { é de acolher, não deixar invisibilizar } \\
\text { o sentimento dos alunos. }\end{array}$} & & \\
\hline & & \multirow{2}{*}{$\begin{array}{l}\text { 7:1 (HOMEM CIS GAY) Atualmente } \\
\text { estou na coordenação do projeto, onde } \\
\text { resolvemos tudo. Atendo jovens que as } \\
\text { vezes chegam em estado de pânico aqui. }\end{array}$} & \multirow{2}{*}{$\begin{array}{l}\text { 14:24 (MULHER TRANS) O projeto para } \\
\text { mim é uma casa, é uma mãe... não é só } \\
\text { social. Me senti acolhida para conversar } \\
\text { sobre tudo sem ser julgada. }\end{array}$} \\
\hline $\begin{array}{l}\text { 15:1 (MULHER TRANS) a gente sai do } \\
\text { projeto, mas o projeto não sai da gente, }\end{array}$ & $\begin{array}{l}\text { 4:30 (HOMEM CIS GAY) no projeto o que } \\
\text { me chamou mais atenção foi o acolhimento, }\end{array}$ & & \\
\hline somos protagonistas o tempo todo. & o fato de poder ser quem eu era. & \multirow{2}{*}{$\begin{array}{l}\text { 14:23 (MULHER TRANS) A dança que me } \\
\text { deu a liberdadede de sair mais de casa, } \\
\text { me socializar mais. }\end{array}$} & \multirow{2}{*}{$\begin{array}{l}\text { 35:8 (MULHER CIS LÉSBICA) projeto } \\
\text { não deu uma luz, não só na minha vida, } \\
\text { mas na vida de muita gente. }\end{array}$} \\
\hline \multirow{2}{*}{$\begin{array}{l}\text { 6:4 (HOMEM CIS GAY) Dança do ventre é } \\
\text { alegria, adoro improvisar, amo soltar } \\
\text { uma música e dançar. }\end{array}$} & \multirow{2}{*}{$\begin{array}{l}\text { 7:5 (HOMEM CIS GAY) Tirar as lágrimas do } \\
\text { outro é bom! Estou aqui, você não está } \\
\text { sozinho é muito bom isso. }\end{array}$} & & \\
\hline & & \multirow{2}{*}{$\begin{array}{l}\text { 6:14 (HOMEM CIS GAY) no projeto faço } \\
\text { algo simples mas que pode fazer } \\
\text { diferença na vida de alguém. }\end{array}$} & \multirow{2}{*}{$\begin{array}{l}\text { 14:28 (MULHER TRANS) pelo projeto já } \\
\text { fiz oficinas, já dei entrevista até para } \\
\text { UNESCO e me senti lisonjeada. }\end{array}$} \\
\hline \multirow{2}{*}{$\begin{array}{l}\text { 14:30 (MULHER TRANS) No projeto foi } \\
\text { a primeira vez que eu me senti alguém! } \\
\begin{array}{l}\text { Foi a primeira vez que me senti escutada } \\
\text { e respeitada. }\end{array}\end{array}$} & \multirow{2}{*}{\begin{tabular}{|l} 
14:25 (MULHER TRANS) A escola sempre \\
foi espaço de agressão, mas na escola do \\
projeto ela se transformou em um \\
ambiente mais harmonioso. Travesti é \\
ameaçada de morte e lá eu nunca fui.
\end{tabular}} & & \\
\hline & & $\begin{array}{l}\text { 14:29 (MULHER TRANS) foi gostoso } \\
\text { colocar várias coisas e falar para outros } \\
\text { e de sensibilizar para passarem pelo } \\
\text { processo de forma menos violenta. }\end{array}$ & $\begin{array}{l}\text { 14:1 (MULHER TRANS) Eu fui para } \\
\text { a escola já sabendo que lá tinham essas } \\
\text { intervenções, o projeto e a dança. }\end{array}$ \\
\hline \multirow{2}{*}{$\begin{array}{l}\text { 14:26 (MULHER TRANS) Eu me } \\
\text { empoderei, eu pude despejar e colocar as } \\
\text { mágoas para fora, aprendi a viver em mais } \\
\text { harmonia com os outros e comigo mesma. }\end{array}$} & \multirow{2}{*}{\multicolumn{2}{|c|}{$\begin{array}{l}\text { 6:13 (HOMEM CIS GAY) Antes de começar no projeto eu não conseguia falar em publico, mas } \\
\text { o curso, o aperfeiçoamento e incentivo foi me dando autonomia de falar, de da aula e falar até } \\
\text { em microfone. }\end{array}$}} & $\begin{array}{l}\text { 5:13 (HOMEM CIS GAY) o projeto me } \\
\text { acolheu e me escutou. }\end{array}$ \\
\hline & & & \\
\hline
\end{tabular}

A partir das narrativas das três jovens LGBT, foram identificados dores, sofrimento e solidão, advindos de processos de violência, preconceito e discriminação, no entanto, é possível depreender outros sentidos dessas histórias. A aproximação das três jovens com a escola que, desde 2001, contabiliza tentativas de mobilização por espaços favoráveis à saúde, é plausível de análise. Dessa forma, a subcategoria apresentada retrata a ascensão na qualidade de vida das jovens em determinada etapa de sua trajetória.

Pelos relatos observa-se a convergência entre o projeto da escola e um espaço de acolhimento: "no projeto o que me chamou a atenção foi o acolhimento e ofato de poder ser quem eu era" (Homem cis gay, 20) e "me senti acolhida para conversar sobre tudo e não ser julgada" (Mulher trans, 20). As jovens expressam o sentir de transformar a escola, em um espaço mais colaborativo e acolhedor. Essa constatação vai ao encontro dos objetivos do desenvolvimento sustentável (ODS) da agenda 2030 da ONU, que propõe assegurar vida saudável e bem-estar para todas as pessoas e idades (Unesco, 2017). O projeto também auxiliou na percepção das identidades e, consequentemente, na melhor relação consigo e com os outros: "o projeto ajudou a me relacionar melhor com as pessoas e comigo mesma" e "no projeto veio a aceitação de ser lésbica" (Mulher cis lésbica, 17); "aprendi a viver com mais harmonia comigo e com os outros" (Mulher trans, 20), qualificando os relacionamentos daqueles que muitas vezes relatavam a solidão e o isolamento social como escudo de proteção ao preconceito.

A escuta ativa, em que vozes ecoam por liberdade de expressão e cidadania, também foi relato convergente nessas falas: "o projeto me acolheu e me escutou" (Homem cis gay, 20); "foi a primeira vez que me senti escutada e respeitada" (Mulher trans, 20). O esvaziamento daquilo que dói pode ser processo terapêutico e o projeto acabou fomentando esse tipo de espaço em suas vidas (Barreto, 2008). Por fim, teve o processo de se perceberem protagonistas de ações de autocuidado e luta por direitos individuais e coletivos. O projeto foi fortalecendo vozes antes emudecidas: "a gente sai do projeto, mas o projeto não sai da gente, somos protagonistas o tempo todo" (Mulher trans, 20); 
"atualmente estou na coordenação do projeto, resolvemos tudo aqui" (Homem cis gay, 20) e "o projeto de entrarnas salas, émuito importante, muda alguns alunos" (Mulher cis lésbica, 17).

Algumas singularidades foram narradas, como, por exemplo, a mulher trans que destacou "no projeto foi a primeira vez que eu me senti alguém", traduzindo o reconhecimento e a valorização de sua existência em contraponto à invisibilidade social vivenciada pelas mulheres trans, partindo do pressuposto de que elas se enquadram no padrão desviante de gênero (Butler, 2002), sendo-lhes negada a convivência afetiva e de pertencimento em condições de visibilidade. Por outro lado, a mulher lésbica destacou que o projeto revolucionou a sua vida mais do que ela imaginava. 0 homem cis gay se declarou envolvido no propósito de acolher os seus pares para que não sofressem o que ele sofreu e contente ao vencer barreiras no processo de comunicação: "antes de começar no projeto, eu não conseguia falar em público, e hoje tenho autonomia para dar aula e falar em microfone". Todos esses aspectos fundamentam uma vida mais pautada em saúde, direitos e cidadania, fortalecendo diretrizes da pedagogia da autonomia como um saber necessário para o processo educacional (Freire, 2019).

Ainda segundo a Unesco, a educação entre pares e o protagonismo juvenil alicerçam outras narrativas possíveis de jovens lideranças, para enfrentamento de dificuldades advindas de uma educação verticalizada, que promove exclusão de potencialidades em prol de controles hegemônicos.

Portanto, processos de educação que se debruçam nesses temas em escolas convergem com um dos domínios da promoção em saúde: a formulação de políticas públicas "saudáveis". De uma perspectiva intersetorial, os sistemas educacionais precisam reconhecer a realidade e as demandas sociais, garantir direitos e proporcionar a ambiência segura e equitativa, que promova uma cultura cidadã de paz e equidade para jovens.

\section{Considerações finais}

A possibilidade de sistematizar algumas das experiências e os sentidos atribuídos pelas três jovens às suas vivências como participantes de projetos escolares de promoção da saúde sexual e reprodutiva contribuem para o fortalecimento desse tema como assunto relevante em cenários escolares. Dar luz ao reconhecimento de pequenas ações pode desafogar quadros de extrema apatia e exclusão para novas possibilidades de construção e inserção da diversidade sexual no cotidiano da vida escolar, além de ser uma oportunidade de formação para estudantes e educadores que produzem reconhecimento, respeito e inclusão de jovens LGBT no contexto das escolas. $O$ maior desafio talvez seja inspirar novos ares e olhares para uma minoria que clama por cidadania e reconhecimento de direitos.

0 estudo mostrou que vivenciar as questões afetivas e sexuais com informações adequadas deve ser direito de todas as pessoas, independentemente de raça, cor, credo ou classe social. Jovens conscientes de seus direitos, fortalecidos pelas suas convergências e valorizados em suas singularidades podem inspirar outras vidas na construção participativa de novos horizontes contra o preconceito e a discriminação sexual e de gênero por meio da educação.

Finalmente, ressalta-se que este estudo tratou da análise de vidas que se cruzam no contexto de um determinado projeto, constituindo uma experiência controlada em tempo e espaço, o que poderia ser uma limitante para se transcender experiências similares em ambientes da vida cotidiana, fora dos espaços de pesquisa. No entanto, a abordagem dessas experiências abre um repertório de intervenções que pode contribuir para minimizar sofrimento e preconceito, desvendar e superar estigmas e fortalecer os processos de cidadania nas escolas.

\section{Referências}

BARDIN, L. Análise de conteúdo. São Paulo: Edições 70, 1977.

BARRETO, A. P. Terapia comunitária passo a passo. Fortaleza: Gráfica LCR, 2008.

BEDIN, R. C. A história do núcleo de estudos da sexualidade e sua participação na trajetória do conhecimento sexual na UNESP. 2016. Tese (Doutorado em Educação Escolar) - Faculdade de Ciências e Letras, Universidade Estadual Paulista Júlio de Mesquita Filho, Araraquara, 2016. 
BELECHE, F. L. K.; SILVA, S. C. A educação em direitos humanos na escola. In: CONGRESSO NACIONAL DE EDUCAÇÃO, 13., 2017, Curitiba. Anais... Curitiba: Pontifícia Universidade Católica do Paraná, 2017.

BOURDIEU, P. A juventude é apenas uma palavra: questões de sociologia. Tradução Jeni Vaitsman. Rio de Janeiro: Marco Zero, 1983.

BRAGA, I. F. et al. Violência familiar contra adolescentes e jovens gays e lésbicas: um estudo qualitativo. Revista Brasileira de Enfermagem, Brasília, DF, v. 71, supl. 3., 2018. DOI:10.1590/o0347167-2017-0307

BRASIL. Programa Saúde na Escola: tecendo caminhos da intersetorialidade. Brasília, DF: Ministério da Saúde, 2011.

BUENO, R. C. P.; RIBEIRO, P. R. M. História da educação sexual no Brasil: apontamentos para reflexão. Revista Brasileira de Sexualidade Humana, Rio de Janeiro, v. 29, n. 1, p. 49-56, 2018. DOI: 10.35919/rbsh.v29i1.41

BUTLER J. Gender trouble: feminism and the subversion of identity. New York: Routledge, 1990.

BUTLER, J. Criticamente subversiva. In: JIMÉNEZ, R. M. M. Sexualidades transgressoras: uma antologia de estúdios queer. Barcelona: Icária, 2002.

DESLANDES, K. Formação de professores e direitos humanos: construindo escolas promotoras da igualdade. Belo Horizonte: Autêntica; Ouro Preto: UFOP, 2015.

DUQUE, E.; TEIXIDO, J. Bullying y género: prevención desde la organización escolar. In: REMIE. Multidisciplinary Journal of Educational Research, Logroño, v. 6, n. 2, p. 176-204, 2016.

FREIRE, P. Pedagogia da autonomia: saberes necessários à prática educativa. 25. ed. São Paulo: Paz e Terra, 2019.

FOUCAULT, M. A história da sexualidade: a vontade de saber. Tradução: Maria Thereza da Costa Albuquerque; José Augusto Guilhon Albuquerque. Rio de Janeiro: Graal, 1988.
JESUS, J. G. de. Orientações sobre identidade de gênero: conceitos e termos. Brasília: Jaqueline Gomes de Jesus, 2012.

KURT, L. J.; CHENAULT, K. H. School policy and transgender identity expression: a study of school administrators' experiences. International Journal of Education Policy and Leadership, Burnaby, v. 12, n. 3, p. 1-17, 2017. DOI: 10.22230/ ijepl.2017v12n3a757

LOURO, G. L. Gênero, sexualidade e educação: uma perspectiva pós-estruturalista. 16. ed. Petrópolis: Vozes, 2017.

MALYON, A. K. Psychotherapeutic implications of internalized homophobia in gay men. Journal of Homosexuality, New York, v. 7, n. 2-3, p. 59-69, 1982. DOI: 10.1300/jo82vo7no2_o8

MUSTANSKI, B.; LIU, R.T. A longitudinal study of predictors of suicide attempts among lesbian, gay, bisexual, and transgender youth. Archives of Sexual Behavior, Berlin, v. 42, n. 3, p. 437-448, 2013. DOI: 10.1007/s10508-012-0013-9

NEVES, M. B. Educação em sexualidade: perspectiva na vida de adolescentes e jovens? São Paulo: Novas Edições Acadêmicas, 2017.

PAIS, J. M. A construção sociológica da juventude: alguns contributos. Análise Social, Lisboa, v. 25, n. 105-106, p. 139-165, 1990.

RUBIN, G. S. Thinking sex: notes for a radical theory of the politics of sexuality. The sex wars. In: VANCE, C. (Ed.). Pleasure and danger: exploring female sexuality. Boston: Routledge \& Kegan Paul, 1984. p. 267-319.

RUSSEL, S. T.; JOYNER, K. Adolescent sexual orientation and suicide risk: evidence from a national study. American Journal of Public Health, Washington, DC, v. 91, n. 8, p. 1276-1281, 2001.

SABIDÓ, M. et al. Sexual violence against men who have sex with men in Brazil: a respondentdriven sampling survey. Aids and Behavior, Berlin, v. 19, n. 9, p. 1630-1641, 2015. DOI: 10.1007/ s10461-015-1016-z

SILVA, C. G.; PAIVA, V.; PARKER, R. Juventude religiosa e homossexualidade: desafios para 
a promoção da saúde e de direitos sexuais.

Interface, Botucatu, v. 17, n. 44, p. 103-117, 2013. DOI: $10.1590 / S 1414-32832013000100009$

SILVA, E. A. S. O estupro corretivo, dupla vulnerabilidade das mulheres LGBTse a urgência de tipificação legal. 2017. Monografia (Bacharelado em Direito) - Centro Universitário Tabosa de Almeida, Caruaru, 2017.
SPARGO, T. Foucault e a teoria queer, seguido de ágape e êxtase: orientações pós-seculares. Tradução Herci Regina. Belo Horizonte: Autêntica, 2017.

UNESCO - ORGANIZAÇÃO DAS NAÇÕES UNIDAS PARA A EDUCAÇÃO, A CIÊNCIA E A CULTURA.

Educação para os objetivos de desenvolvimento sustentável: objetivos de aprendizagem. Brasília, DF: Unesco Brasil, 2017.

\section{Contribuição dos autores}

Freitas coletou os dados e os processou com Bermúdez. Todos os autores desenharam o projeto, analisaram os dados e redigiram o artigo.

Recebido: 09/10/2019

Reapresentado: 23/08/2020

Aprovado: 14/10/2020 